Gut, 1978, 19, 10-13

\title{
Effect of glucocorticoids on gastrin secretion in man
}

\author{
S. SEINO, Y. SEINO, S. MATSUKURA, H. KURAHACHI, M. IKEDA, \\ M. YAWATA, AND H. IMURA \\ From the Third Division, Department of Medicine, Kobe University School of Medicine, \\ the Second Division, Department of Medicine, Hamamatsu Medical College and Department of \\ Endocrinology, Kitano Hospital, Japan
}

SUMMARY In order to investigate the effect of glucocorticoids on gastrin secretion, plasma gastrin levels were measured by radioimmunoassay in patients with Cushing's syndrome and those treated with glucocorticoids. Fasting plasma gastrin levels were significantly higher in these patients than in normal subjects, with exaggerated response to food. Conversely, short-term treatment or intravenous infusion of glucocorticoids had no significant influence on gastrin secretion in normal subjects. The possible mechanism by which glucocorticoids cause hypergastrinaemia are discussed.

It is well-known that 'steroid ulcer' is a frequent complication of treatment with glucocorticoids(Bollet et al., 1955; Meltzer et al., 1958), although the pathogenesis of this untoward complication still remains obscure. Accumulating evidence in recent years has suggested that gastrin is an important ulcerogenic factor among gastrointestinal hormones (Trudeau $e t$ al., 1970; Gedde-Dahl, 1974; Walsh et al., 1975). To our knowledge, however, very few studies have been reported on the effect of glucocorticoids on gastrin secretion (Watson et al., 1973; Giordano and Marugo, 1974; Raptis et al., 1976).

The present study was designed to investigate the acute and chronic effect of glucocorticoids on plasma gastrin levels in man.

\section{Methods}

\section{FASTING GASTRIN LEVELS}

\section{Normal subjects}

Forty-five normal subjects, 25 men and 20 women, aged 18 to 52 years, were used as controls. Their endocrine and gastrointestinal functions were apparently normal.

\section{Subjects on short-term treatment with glucocorticoids}

Eleven normal subjects, six men and five women,

Address for correspondence: Dr Susumu Seino, Third Division, Department of Medicine, Kobe University School of Medicine, Kusunoki-cho, Ikuta-ku, Kobe, Japan.

Received for publication 22 June 1977 aged 25 to 50 years, were studied after three days of oral prednisolone administration $(30 \mathrm{mg} /$ day).

\section{Subjects on long-term treatment with glucocorticoids}

A group of 10 patients was studied, which comprised five with bronchial asthma, two with collagen disease, two with idiopathic thrombocytopenic purpura, and one with polyneuropathy. These patients, five men and five women, aged 23 to 58 years, were thought to have no gastrointestinal disorders or abnormalities in renal function. They had received more than 500 $\mathrm{mg}$ (prednisolone equivalent) glucocorticoids altogether and for longer than three weeks. Anticholinergic drugs were withheld for at least five days before the experiment.

\section{Cushing's syndrome}

Six patients (two men and four women, aged 17 to 52 years), had Cushing's syndrome, surgically proven to be caused by bilateral adrenal hyperplasia. In two of these patients, fasting plasma gastrin levels were retested after their clinical symptoms had disappeared and their laboratory data had become normal by treatment.

\section{EFFECT OF FOOD}

In order to study the response of plasma gastrin to food, test meals were given to six untreated normal subjects, six subjects on short-term treatment with glucocorticoids, and six patients on long-term treatment with glucocorticoids. The meal consisted of 80 $\mathrm{g}$ carbohydrate, $15 \mathrm{~g}$ protein, and $10 \mathrm{~g}$ fat. The blood samples were obtained before and again 30 and 60 minutes after the meal. 


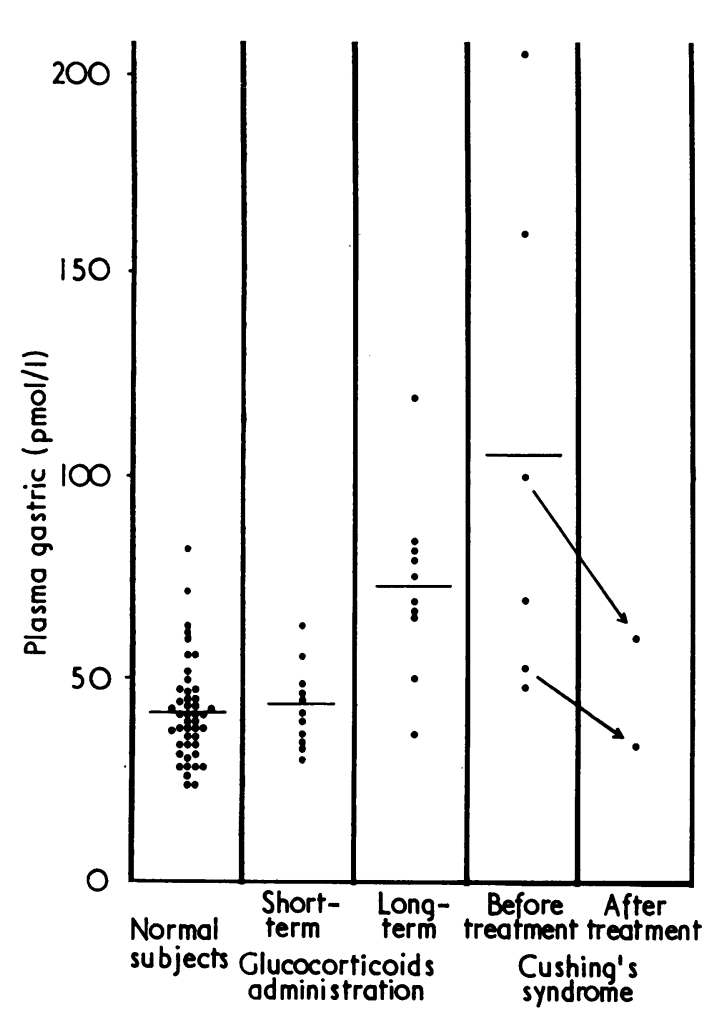

Fig. 1 Fasting plasma gastrin levels in untreated normal subjects, in subjects on short-term glucocorticoid treatment, and in patients on long-term glucocorticoid treatment and Cushing's syndrome.

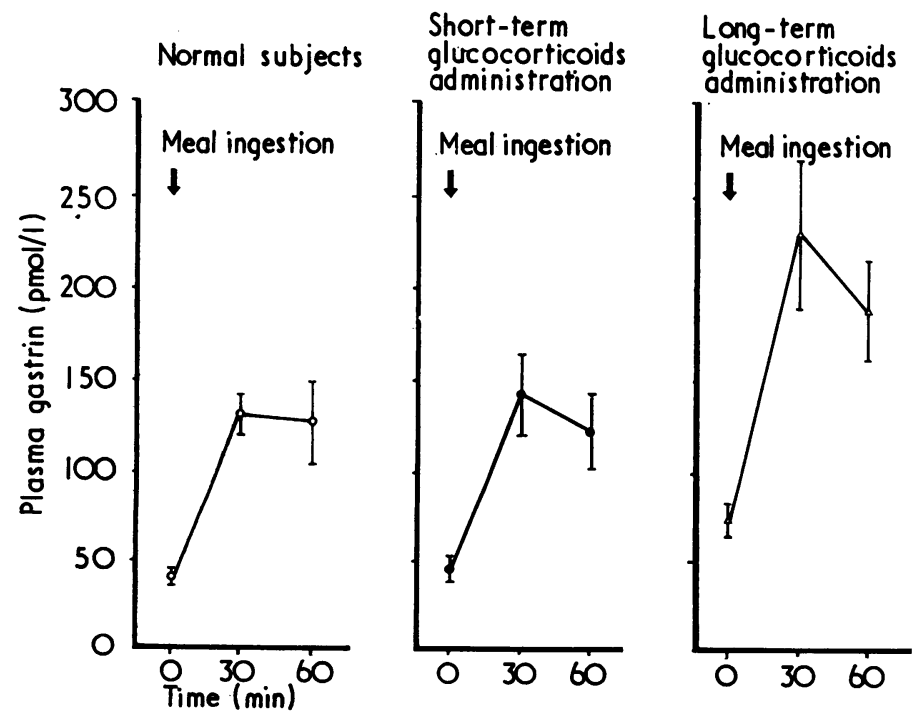

INTRAVENOUS INFUSION OF

\section{GLUCOCORTICOIDS}

To study the acute effect of glucocorticoids on gastrin secretion, five normal male volunteers, aged 21 to 38 years, were subjected to the following two experiments with an interval of at least one week between two tests. Either $250 \mathrm{mg}$ or $500 \mathrm{mg}$ hydrocortisone dissolved in $250 \mathrm{ml}$ saline were administered to them intravenously over a period of 60 minutes. Blood was withdrawn immediately before and at intervals of 15 minutes after the start of the infusion as indicated in Fig. 3. All volunteers were informed of the nature, purpose, and potential risks of the procedure.

All experiments mentioned above were conducted in the early morning after an overnight fast and absolute bed rest for at least 30 minutes.

Blood was withdrawn into a heparinised disposable plastic syringe from the antecubital vein. An aliquot of the blood was used for determining blood glucose, using the Technicon AutoAnalyzer (Hoffman, 1937). The remaining portion was centrifuged and plasma was separated, frozen, and stored at $-20^{\circ} \mathrm{C}$ until assayed. Plasma gastrin was measured by dextran-coated charcoal radioimmunoassay as previously described (Seino et al., 1976).

Statistical analysis was performed using either Student's $t$ test or the paired $t$ test.

\section{Results}

FASTING GASTRIN LEVELS (Fig. 1)

The mean $( \pm S E)$ fasting plasma gastrin levels in 

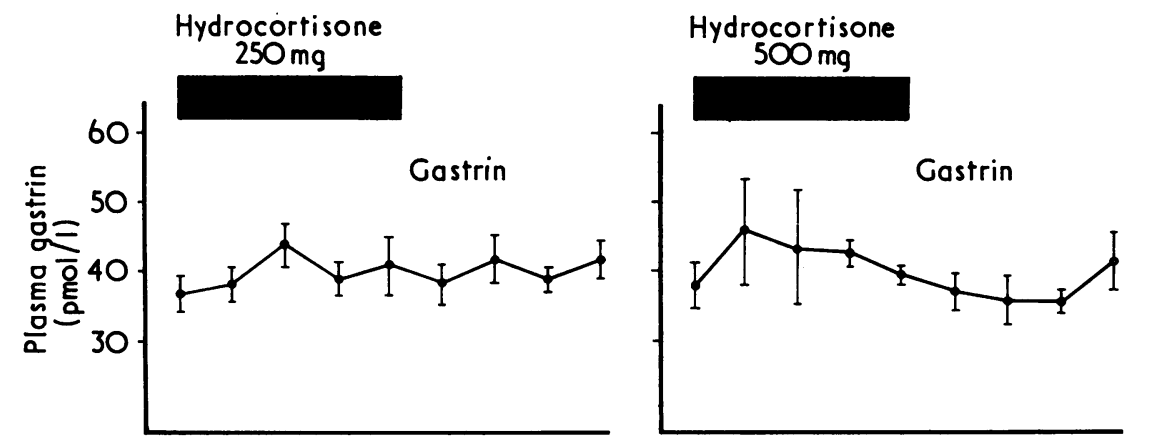

Fig. 3 Effect of hydrocortisone infusion on plasma gastrin and blood glucose levels in normal subjects. Means $\pm S E$ are shown.
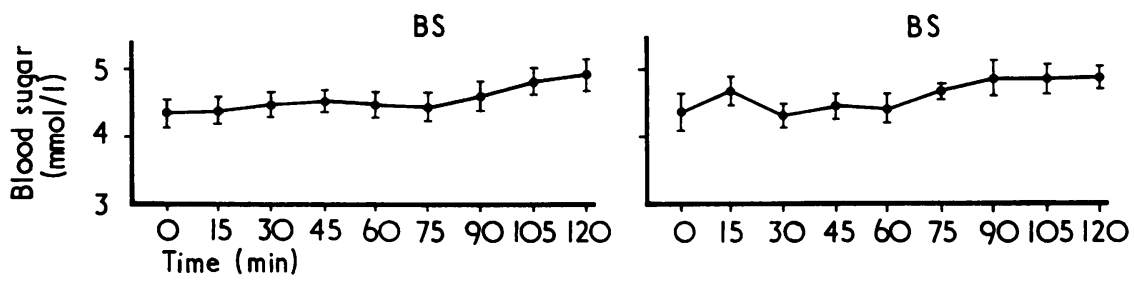

untreated normal subjects and those on short-term glucocorticoid treatment were $43 \pm 2 \mathrm{pmol} / 1$ and $43 \pm 3 \mathrm{pmol} / \mathrm{l}$, which were not significantly different from each other. In contrast, patients receiving longterm glucocorticoid treatment and those with Cushing's syndrome had plasma gastrin levels of $73 \pm 10 \mathrm{pmol} / 1$ and $105 \pm 20 \mathrm{pmol} / \mathrm{l}$, both of which were significantly higher than that in normal subjects $(\mathrm{P}<0.01)$.

When plasma gastrin levels were retested after treatment in two patients with Cushing's syndrome, they had dropped towards the normal range.

\section{PLASMA GASTRIN RESPONSE TO FOOD}

(Fig. 2)

In normal subjects, the ingestion of the test meal caused a significant increase in plasma gastrin from the basal levels of $40 \pm 5 \mathrm{pmol} / \mathrm{l}$ to the levels of $131 \pm 11 \mathrm{pmol} / 1$ and $127 \pm 24 \mathrm{pmol} / \mathrm{l}$ at 30 and 60 minutes, respectively. A similar response of plasma gastrin to food was observed in normal subjects treated with glucocorticoids for three days, showing the mean basal and postprandial ( 30 and 60 minutes) levels of $47 \pm 5 \mathrm{pmol} / \mathrm{l}, 144 \pm 23 \mathrm{pmol} / \mathrm{l}$, and 124 $\pm 21 \mathrm{pmol} / \mathrm{l}$, respectively. These values were not significantly different from those in untreated normal subjects.

On the other hand, food caused an exaggerated response of plasma gastrin in patients treated with glucocorticoid for more than three months. The mean basal and 30 minute postprandial plasma gastrin levels, $74 \pm 10 \mathrm{pmol} / 1$ and $231 \pm 41$ pmol/l, respectively, were significantly higher than the corresponding values in untreated normal subjects $(P<0.05)$.

PLASMA GASTRIN RESPONSE TO INTRAVENOUS INFUSION OF HYDROCORTISONE (Fig. 3)

Intravenous infusion of $250 \mathrm{mg}$ hydrocortisone caused a slight but insignificant increase of plasma gastrin, with the highest value of $43 \pm 3 \mathrm{pmol} / 1$ occurring at 30 minutes $(\mathrm{P}>0.05$ vs preinfusion level). A larger dose of hydrocortisone (500 mg) also caused a slight increase in plasma gastrin, with the highest value of $45 \pm 8 \mathrm{pmol} / \mathrm{l}$ at 15 minutes, which was not significantly different from the basal level (P > 0.05). Blood glucose tended to rise, though not significantly, during the infusion of hydrocortisone.

\section{Discussion}

The present experiments demonstrate that basal plasma gastrin levels were raised, with an exaggerated response to food in patients on long-term treatment with glucocorticoids or with Cushing's syndrome. However, short-term treatment with glucocorticoids or acute infusion of hydrocortisone, even at a dose of $500 \mathrm{mg}$, had no significant effect. These results suggest that chronic exogenous or endogenous excess of glucocorticoids leads to hypergastrinaemia, whereas an acute excess has no significant influence on gastrin secretion.

Watson et al. (1973) and Raptis et al. (1976) reported that a bolus injection of glucocorticoids did not increase plasma gastrin, although four to five 
days' treatment significantly enhanced both basal and stimulated gastrin secretion. These results partly disagree with our observation, that three days' treatment with glucocorticoids failed to influence either basal or stimulated gastrin secretion. The reason for this discrepancy may be explained by the difference in the total dose and duration of glucocorticoid treatment between experiments. The mechanism responsible for hypergastrinaemia induced by chronic excess of glucocorticoid, though not clear at present, deserves consideration. There seem to be several possible explanations for this phenomenon. First, glucocorticoids may act directly on gastrin secretion cell (G-cell), resulting in G-cell hyperplasia and hyperfunction. However, there has been no report on the histology of G-cells in glucocorticoid-treated animals or man.

Second, it is possible that glucocorticoids cause inhibition of gastric acid secretion, which, in turn, stimulates gastrin secretion through a negative feedback mechanism. Controversial results have been reported on the influence of glucocorticoids on gastric acid secretion. Some investigators reported increased gastric acidity (Villarreal et al., 1955; Cooke and Grossman, 1966), while others observed no significant change or rather a decrease in gastric acidity in patients on treatment with glucocorticoids (Hirschowitz et al., 1955; Dragstedt et al., 1956). Although gastric acidity was not measured in the present experiment, inconsistent results in the previous experiments seem to militate against the second possibility.

The third and most likely explanation is that metabolic changes-for example, an increase of plasma amino acids-induced by glucocorticoids are responsible for enhanced gastrin secretion. In fact, protein catabolic effect of glucocorticoids has been well documented (Long et al., 1940; Smith et al., 1967) and an increase of plasma amino acids has been reported in patients with Cushing's syndrome or those treated with glucocorticoids (Wise et al., 1973). As some amino acids are reported to be potent secretagogues of gastrin (Kalk et al., 1973; Debas et al., 1974), the increased plasma levels of amino acids induced by glucocorticoids may enhance gastrin secretion. The fact that chronic excess of glucocorticoids is a prerequisite for hypergastrinaemia may also favour the metabolism hypothesis. Further investigations should clarify the exact mechanism responsible for glucocorticoid-induced gastrin secretion.

\section{References}

Bollet, A. J., Black, R., and Bunim, J. J. (1955). Major undesirable side-effects resulting from prednisolone and prednisone. Journal of the American Medical Association, 158, 459-463.

Cooke, A. R., and Grossman, M. I. (1966). Effect of hydrocortisone on secretion of acid and pepsin by Heidenhain pouches. Proceedings of the Society for Experimental Biology and Medicine, 123, 704-707.

Debas, H. T., Csendes, A., Walsh, J. H., and Grossman, M. I. (1974). Release of gastrin. In Endocrinology of the Gut, pp. 222-232. Edited by W. Y. Chey and F. B. Brooks. Slack, Thorofare: New Jersey.

Dragstedt, L. R., Ragins, H., Dragstedt, L. R. II., and Evans, S. O., Jr. (1956). Stress and duodenal ulcer. Annals of Surgery, 144, 450-463.

Gedde-Dahl, D. (1974). Radioimmunoassay of gastrin. Fasting serum levels in humans with normal and high gastric acid secretion. Scandinavian Journal of Gastroenterology, 9, 41-47.

Giordano, G., and Marugo, M. (1974). Comportamento della gastrina ematica nell'uomo dopo carico endovenoso di cortisolo. Bollettino della Societa Iialiana di Biologia Sperimentale, 50, 1905-1910.

Hirschowitz, B. I., Streeten, D. H. P., Pollard, H. M., and Boldt, H. I., Jr (1955). Role of gastric secretions in activation of peptic ulcers by corticotropin (ACTH). Journal of the American Medical Association, 158, 27-32.

Hoffman, W. S. (1937). A rapid photoelectric method for determination of glucose in blood and urine. Journal of Biological Chemistry, 120, 51-55.

Kalk, W. J., Vinik, A. I., Bank, S., Hayes, J. R., Ardill, J., Buchanan, K. D., Keller, P., and Jackson, W. P. U. (1974). Plasma gastrin responses to arginine in chronic pancreatitis. Diabetes, 23, 264-267.

Long, C. N. H., Katzin, H. B., and Fry, E. G. (1940). The adrenal cortex and carbohydrate metabolism. Endocrinology, 26, 309-344.

Meltzer, L. E., Bockman, A. A., Kanenson, W., and Cohen, A. (1958). The incidence of peptic ulcer among patients on long term prednisone therapy. Gastroenterology, 35, 351356.

Raptis, S., von Berger, L., Dollinger, H. C., Fazekas, A. T. A., and Pfeiffer, E. F. (1976). Hypergastrinemia induced by glucocorticoid and corticotropin treatment in man. American Journal of Digestive Diseases, 21, 376-380.

Seino, Y., Matsukura, S., Miyamoto, Y., Goto, Y., Taminato, T., and Imura, H. (1976). Hypergastrinemia in hyperthyroidism. Journal of Clinical Endocrinology and Metabolism, 43, 852-855.

Smith, O. K., and Long, C. N. H. (1967). Effect of cortisol on the plasma amino nitrogen of eviscerated adrenalectomizeddiabetic rats. Endocrinology, 80, 561-566.

Trudeau, W. L., and McGuigan, J. E. (1970). Serum gastrin levels in patients with peptic ulcer disease. Gastroenterology, 59, 6-12.

Villarreal, R., Ganong, W. F., and Gray, S. J. (1955). Effect of adrenocorticotrophic hormone upon the gastric secretion of hydrochloric acid, pepsin and electrolytes in the dog. American Journal of Physiology, 183, 485-494.

Walsh, J. H., Richardson, C. T., and Fordtran, J. S. (1975). $\mathrm{pH}$ dependence of acid secretion and gastrin release in normal and ulcer subjects. Journal of Clinical Investigation, $55,462-468$.

Watson, L. C., Reeder, D. D., and Thompson, J. C. (1973). Effect of hydrocortisone on gastric secretion and serum gastrin in dogs. Surgical Forum, 24, 354-356.

Wise, J. K., Hendler, R., and Felig, P. (1973). Influence of glucocorticoids on glucagon secretion and plasma amino acid concentrations in man. Journal of Clinical Investigation, 52, 2774-2782. 